\title{
MUDANÇAS NA ESTRUTURA DA VEGETAÇÃO LENHOSA EM TRÊS PORÇÕES DA MATA DE GALERIA DO CÓRREGO BACABA (1999-2006), NOVA XAVANTINA-MT ${ }^{1}$
}

\author{
Aline Miguel ${ }^{2}$, Beatriz Schwantes Marimon ${ }^{3}$, Leandro Maracahipes ${ }^{4}$, Edmar Almeida de Oliveira ${ }^{4}$ e \\ Ben Hur Marimon Junior ${ }^{3}$
}

\begin{abstract}
RESUMO - Este estudo, realizado na Mata de Galeria do córrego Bacaba (1441'S e 52²0’W), em Nova Xavantina, MT, avaliou as mudanças na estrutura da vegetação no período de 1999 a 2006. Em 1999, foram demarcadas 141 parcelas permanentes em três porções da mata (alto, meio e baixo), em um gradiente topográfico, e medidos os indivíduos com CAP $\geq 15 \mathrm{~cm}$. No inventário de 2006, os indivíduos foram remedidos e os recrutas, computados. Em 2006, amostraram-se 135 espécies, 113 gêneros e 49 famílias. A posição hierárquica das espécies apresentou mudanças expressivas em relação a 1999. Na porção do alto, as espécies com maior valor de importância (VI) foram: Astrocaryum vulgare, Diospyros guianensis e Calophyllum brasiliense. Essa porção pode ter sido a mais afetada pelo fogo que atingiu a área em 2001, visto que uma espécie típica de ambientes antropizados passou a ocupar a primeira posição de VI. No meio, as espécies mais importantes em 2006 foram: Aspidosperma subincanum, Tetragastris altissima e Hymenaea courbaril. No baixo, apenas Mauritia flexuosa manteve a mesma posição do inventário anterior, e a maior alteração hierárquica foi apresentada pelas espécies pioneiras, sugerindo um fechamento da vegetação. Entre as 10 espécies de maior VI em 2006, nenhuma foi comum às três porções da mata. Características estruturais distintas da vegetação entre áreas geograficamente tão próximas podem estar relacionadas à heterogeneidade do ambiente. As mudanças no VI registradas nas espécies das três porções de mata reforçam a ideia de que esta apresenta elevada dinâmica.
\end{abstract}

Palavras-chave: Astrocaryum vulgare, Heterogeneidade ambiental e Floresta ripária.

\section{CHANGES IN THE STRUCTURE OF THE WOODY VEGETATION IN THREE PORTIONS OF THE GALLERY FOREST OF THE BACABA STREAM (1999-2006), NOVA XAVANTINA-MT}

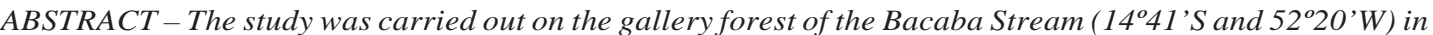
Nova Xavantina-MT. It evaluated the changes in the structure of the vegetation from 1999 to 2006. In 1999, it was delimited 141 permanent plots in three portions of the gallery forest (upper, middle and lower), in a topographic gradient, and all individuals with breast height circumference $\geq 15 \mathrm{~cm}$ were measured. In the 2006 inventory, it was sampled 135 species, 113 genera and 49 families. The hierarchical position of the species showed significant changes in comparison to 1999. In the upper portion the most important species (IV) were: Astrocaryum vulgare, Diospyros guianensis and Calophyllum brasiliense. This portion could have been the most affected by the fire which occurred in 2001 inasmuch as one typical species of anthropic system occupied the first VI place. In the middle, the most important species in 2006 were: Aspidosperma subincanum, Tetragastris altissima and Hymenaea
\end{abstract}

\footnotetext{
${ }^{1}$ Recebido em 13.08.2008 e aceito para publicação em 18.04.2011.

${ }^{2}$ Programa de Pós-graduação em Ciências Ambientais, Universidade do Estado de Mato Grosso, UNEMAT, Campus de Cáceres, Cáceres, MT, Brasil. E-mail: <alinemiguelbio@gmail.com>.

${ }^{3}$ Departamento de Ciências Biológicas, Universidade do Estado de Mato Grosso, Campus de Nova Xavantina, MT, Brasil. E-mail: <biamarimon@hotmail.com>e <bhmjunior@gmail.com>.

${ }^{4}$ Programa de Pós-graduação em Ecologia e Conservação, Universidade do Estado de Mato Grosso, Campus de Nova Xavantina, MT, Brasil.E-mail: <lmaracahipes@gmail.com>e <edmardinei@hotmail.com>.
} 
courbaril. In the lower, only Mauritia flexuosa maintained the same hierarchical position in the previous hierarchical inventory, the greatest hierarchical change was presented by the pioneer species, suggesting a vegetation closure. Of the 10 species with the greatest IV in 2006, none was common to the three forest portions. Distinct vegetation structure traits among areas geographically so close may be related to environmental heterogeneity. Changes in IV recorded in species of the three forest portions reinforce the idea that this one presents a high dynamics.

Keywords: Astrocaryum vulgare, Environmental heterogeneity and Riparian forest.

\section{INTRODUÇÃO}

As matas de galeria são notadamente compostas por uma flora muito diversa, sendo extremamente importantes para a fauna do Cerrado, agindo como corredores de migração (OLIVEIRA-FILHO; RATTER, 1995). Essa fitofisionomia tropical está entre as que despertam maior interesse em estudos ecológicos, pois apresenta características particulares, tanto em aspectos bióticos quanto abióticos (PINTO; OLIVEIRA-FILHO, 1999). Nesse caso, os fatores físicos locais, como variações edáficas e topográficas, influenciam na vegetação das Matas de Galeria, além de perturbações naturais e antrópicas frequentes, que causam alterações em sua composição florística e na estrutura da vegetação, como o fogo e as enchentes sazonais (FELFILI, 1995; RODRIGUES, 2000; BATTILANI et al., 2005).

Comunidades e populações de espécies lenhosas de florestas tropicais podem apresentar mudanças temporais de densidade e área basal, sugerindo que a estrutura é dinâmica (FELFILI, 1994, 1995). Em uma floresta de vale na Chapada dos Guimarães, MT, Pinto e Hay (2005) registraram taxas de mudança positivas em árvores e arvoretas em diferentes hábitats. Em um estudo realizado em 25 florestas neo e paleotropicais, Phillips e Gentry (1994) registraram que a riqueza pode ser explicada pela dinâmica da comunidade, apesar de Pinto (2002) sugerir que em muitos casos essa hipótese não seria apropriada para explicar a riqueza dentro de determinada área (diversidade alfa).

Os levantamentos florísticos permitem realizar comparações simples e eficientes entre grande número de áreas. Entretanto, somente os levantamentos fitossociológicos podem fornecer informações sobre semelhanças e diferenças na estrutura da vegetação entre áreas floristicamente similares, podendo ser mais bem abordadas através de dados quantitativos, pois as diferenças estruturais podem ser mais marcantes que as diferenças florísticas (VAN DEN BERG; OLIVEIRA-FILHO, 2000). Existem diversos trabalhos fitossociológicos realizados em diferentes intervalos de tempo, no entanto a maioria desses levantamentos discute resultados baseados em apenas uma única observação (OLIVEIRA-FILHO, 1989; MARIMON et al., 2002; BATTILANI et al., 2005), não analisando as mudanças florísticas e estruturais das comunidades ao longo do tempo (WERNECK et al., 2000; PINTO; HAY, 2005; MELO et al., 2007).

Diversos estudos vêm demonstrando que as florestas tropicais podem ser vulneráveis ao fogo, apresentando alterações na sua estrutura e dinâmica (NEPSTAD et al., 2004; BALCH et al., 2008). Nesse contexto, na porção leste do Estado de Mato Grosso o avanço da fronteira agropecuária e a pressão de desmatamentos acompanhados de queimadas (NEPSTAD et al., 2002; BALCH et al., 2008) vêm colocando cada vez mais em risco a manutenção da diversidade das florestas na região e representam grande ameaça à biodiversidade (MARIMON et al., 2006).

Os objetivos deste estudo foram analisar e descrever as mudanças que ocorreram na estrutura da vegetação lenhosa da Mata de Galeria do córrego Bacaba, localizada no Parque Municipal do Bacaba, em Nova Xavantina, MT, em um período de sete anos (1999 a 2006), com a ocorrência de uma queimada entre os dois inventários.

\section{MATERIAL E MÉTODOS}

\section{1. Área de estudo}

O trabalho foi realizado em três porções localizadas em um gradiente topográfico (doravante denominadas de alto, meio e baixo) da Mata de Galeria do córrego Bacaba (1441'25”S e 52²0’55”'W), no Parque Municipal do Bacaba, em Nova Xavantina, Mato Grosso. A água do córrego Bacaba abastece um bairro residencial do município, sem tratamento prévio. A altitude média é de 346 m e o clima é do tipo Aw, segundo a classificação de Köppen, com precipitação anual de 1.300 a 1.500 mm e temperatura média mensal de $25^{\circ} \mathrm{C}$ (MARIMON et al., 2003; 2010).

A porção do alto apresenta declividade média de $42 \%$, com presença de afloramentos rochosos de quartzito e ocorrência de enchentes sazonais com

Revista Árvore, Viçosa-MG, v.35, n.3, Edição Especial, p.725-735, 2011 
drenagem rápida. O meio apresenta declividade de aproximadamente 32\%, com afloramentos rochosos, e em locais com menor declividade o lençol freático aflora no período chuvoso e o baixo, com reduzida declividade (cerca de 5\%), não apresenta afloramentos rochosos, e a drenagem do solo é deficiente (MARIMON et al., 2001; 2002; 2003). Em julho de 2001 foi registrada uma queimada no Parque que também atingiu parte da Mata de Galeria estudada. O fogo originou-se de uma fazenda adjacente, cujo proprietário utilizava a prática de queimadas para renovar o pasto no período da seca (maio-setembro). Mais de $70 \%$ das parcelas avaliadas neste estudo foram atingidas pelo fogo em diferentes proporções e intensidades. Apesar de o fogo ter adentrado na área, o Parque era cercado e não havia a presença de gado ou outros distúrbios diretos.

\subsection{Amostragem da vegetação}

No ano de 1999 foram estabelecidas 141 parcelas permanentes de 10 x 10 m, visando a uma caracterização fitossociológica e estrutural da vegetação (MARIMON et al., 2001; 2002; 2003). As parcelas foram posicionadas contínua e sistematicamente, cobrindo toda a área ocupada pela mata, desde a margem do córrego até o encontro com o cerrado stricto sensu. Em cada porção (alto, meio e baixo) foram demarcadas 47 parcelas perpendiculares ao córrego.

Em 1999, todas as árvores, arvoretas, palmeiras, lianas ou indivíduos mortos em pé com CAP (circunferência à altura do peito) $\geq 15 \mathrm{~cm}$ foram identificados e medidos (MARIMON et al., 2002). No ano de 2006 (este estudo), todos os indivíduos amostrados no primeiro inventário foram remedidos juntamente com aqueles que atingiram a circunferência mínima de inclusão (recrutas).

De cada espécie amostrada foi coletado, no mínimo, um número de herbário (Voucher) para comprovar sua identificação. Por um período mínimo de um ano, foram realizadas visitas quinzenais às parcelas onde foram coletadas todas as espécies encontradas com material reprodutivo. Coletaram-se no mínimo quatro duplicatas para compor a coleção do Herbário NX e permitir o envio a especialistas. Os nomes das espécies foram conferidos em MOBOT (2007).

\subsection{Parâmetros fitossociológicos}

Para a descrição da estrutura da vegetação (espécies e famílias) de cada porção da Mata de Galeria do córrego Bacaba, foram utilizados os parâmetros: densidade, frequência e dominância absolutas e relativas e o valor de importância (VI), conforme Müeller-Dombois e Ellenberg (1974). Os resultados do inventário realizado em 1999 (MARIMON et al., 2002) foram comparados com os parâmetros determinados no inventário de 2006. Para as análises, foi utilizado o programa FITOPAC 1.0 (SHEPHERD, 1994).

\section{RESULTADOS E DISCUSSÃO}

Considerando-se as três porções de mata (alto, meio e baixo), foram amostrados 135 espécies, 113 gêneros e 49 famílias botânicas (Tabelas 1, 2 e 3). Em relação ao levantamento de 1999, houve aumento, sendo naquela ocasião registrados 129 espécies, 105 gêneros e 47 famílias (MARIMON et al., 2002).

No alto, 22 espécies apresentaram apenas um indivíduo, sendo consideradas raras, correspondendo a 28,6\% do número total das espécies e 5,1\% do VI (valor de importância). No meio foram registradas 26 espécies com apenas um indivíduo (29,5\% das espécies e $6,8 \%$ do VI) e, no baixo, 20 espécies raras $(8,1 \%$ e $3,8 \%$, respectivamente). Valores próximos (25,7 a 27,9\% das espécies e de 4,4 a 6,3\% do VI) também foram encontrados em outros estudos em Matas de Galeria (PINTO; OLIVEIRA-FILHO, 1999; PINTO; HAY, 2005; BATTILANI et al., 2005). Pinto e Hay (2005) registraram que esse é um resultado esperado em florestas tropicais, sendo de $1 / 4$ a 1/3 das espécies amostradas com baixa densidade.

Em 1999, na porção do alto as espécies raras foram representadas por 20,3\% do número total de espécies e $4,3 \%$ do VI total, no meio $21 \%$ e $4,2 \%$ e no baixo 26\% e 3,3\%, respectivamente. Em 2006, houve aumento no número de espécies raras nas três porções da mata. Entretanto, em ambos os levantamentos o percentual esteve dentro dos valores indicados por Battilani et al. (2005) e Silva-Júnior et al. (2001).

Em 2006, na porção do alto 20\% das espécies concentraram 59\% dos indivíduos, 51,5\% no meio e $64,7 \%$ no baixo, valores próximos aos registrados em 1999 por Marimon et al. (2002), na mesma mata, e por Pinto e Hay (2005) em uma floresta de vale na Chapada dos Guimarães, MT (56 a 58\%). Isso indica que o padrão de concentrar a maior parte dos indivíduos em poucas espécies (FELFILI et al., 2001a) tende a se manter com o passar dos anos em Matas de Galeria da região central do Brasil (PINTO; HAY, 2005). 


\subsection{Porção do alto}

Em 2006, a densidade absoluta registrada na porção do alto foi de 1.070 ind. ha-1 , com uma área basal de 22,18 $\mathrm{m}^{2} \mathrm{ha}^{-1}$. As 10 espécies de maior valor de importância (VI) representaram juntas $43,2 \%$ do VI total, $68,4 \%$ do número de indivíduos amostrados e 45,7\% da área basal total (Tabela 1). O componente mais importante da espécie de maior VI, Astrocaryum vulgare, foi a densidade, que, juntamente com Diospyros guianensis, também apresentou os maiores valores de frequência. Calophyllum brasiliense, com apenas 13 indivíduos, destacou-se com a maior dominância (Tabela 1).

Comparando com o inventário de 1999 (MARIMON et al., 2002), em que a densidade absoluta foi de 972 ind.ha ${ }^{-1}$ e a área basal de 19,6 m² $\mathrm{ha}^{-1}$, em 2006, apesar da queimada registrada em 2001, os aumentos em área basal e densidade podem estar de acordo com o que foi observado por Baker et al. (2004),

Tabela 1 - Parâmetros fitossociológicos das espécies principais amostradas na porção do alto na Mata de Galeria do córrego Bacaba, Nova Xavantina, MT. Sendo: N = número de indivíduos, DR = Densidade relativa (\%), DoR = Dominância relativa (\%), FR = Frequência relativa (\%) e VI = Valor de importância.

Table 1 - Phytosociological parameters for principal species sampled in the upper portion of the Bacaba gallery forest, Nova Xavantina-MT. $N=$ number of individuals, $D R=$ relative density $(\%), D o R=$ relative dominance $(\%), F R$ = relative frequency $(\%)$ and $V I=$ importance value.

\begin{tabular}{|c|c|c|c|c|c|}
\hline Espécies & $\mathrm{N}$ & DR & DoR & FR & VI \\
\hline Astrocaryum vulgare Mart. & 82 & 16,30 & 4,38 & 4,80 & 25,49 \\
\hline Diospyros guianensis (Aubl.) Gürke & 45 & 8,95 & 7,36 & 5,71 & 22,01 \\
\hline Calophyllum brasiliense Cambess & 13 & 2,58 & 8,09 & 2,40 & 13,08 \\
\hline Mabea pohliana (Benth.) Müll. Arg. & 22 & 4,37 & 2,52 & 4,50 & 11,4 \\
\hline Protium heptaphyllum (Aubl.)Marchand & 18 & 3,58 & 3,19 & 4,20 & 10,97 \\
\hline Licania blackii Prance & 16 & 3,18 & 3,46 & 3,30 & 9,95 \\
\hline Oenocarpus distichus Mart. & 15 & 2,98 & 2,99 & 3,60 & 9,58 \\
\hline Apuleia leiocarpa (Vog.) Macbr. & 9 & 1,79 & 5,56 & 2,10 & 9,45 \\
\hline Tetragastris altissima (Aubl.) Swart. & 15 & 2,98 & 2,03 & 4,20 & 9,22 \\
\hline Hymenaea courbaril L. & 5 & 0,99 & 6,11 & 1,50 & 8,61 \\
\hline Tapirira guianensis Aubl. & 7 & 1,39 & 4,83 & 1,80 & 8,02 \\
\hline Licania apetala (E. Mey) Fritsch & 14 & 2,78 & 2,13 & 3,00 & 7,92 \\
\hline Physocalymma scaberrimum Pohl. & 9 & 1,79 & 3,41 & 2,70 & 7,90 \\
\hline Himatanthus bracteatus (A.DC.) Woodson & 14 & 2,78 & 1,91 & 2,70 & 7,40 \\
\hline Aspidosperma subincanum Mart. & 13 & 2,58 & 1,97 & 2,70 & 7,26 \\
\hline Protium spruceanum (Benth.) Engl. & 6 & 1,19 & 3,79 & 1,50 & 6,49 \\
\hline Ephedranthus parviflorus S. Moore & 13 & 2,58 & 1,42 & 2,10 & 6,11 \\
\hline Inga thibaudiana DC. & 10 & 1,99 & 1,74 & 1,80 & 5,53 \\
\hline Luehea candicans Mart. & 8 & 1,59 & 1,21 & 2,40 & 5,20 \\
\hline Ormosia coarctata Jacks. & 10 & 1,99 & 1,40 & 1,80 & 5,19 \\
\hline Vitex polygama Cham. & 5 & 0,99 & 2,64 & 1,50 & 5,13 \\
\hline Pseudolmedia laevigata Trécul & 9 & 1,79 & 1,17 & 2,10 & 5,07 \\
\hline Tachigali vulgaris L.G. Silva \& H.C. Lima & 6 & 1,19 & 2,06 & 1,80 & 5,06 \\
\hline Andira vermifuga Mart. ex Benth & 3 & 0,60 & 3,46 & 0,90 & 4,96 \\
\hline Myrcia sellowiana O. Berg. & 7 & 1,39 & 1,22 & 1,80 & 4,41 \\
\hline Licania gardneri (Hook.f.) Fritsch & 6 & 1,19 & 1,29 & 1,80 & 4,29 \\
\hline Astronium fraxinifolium Schott. & 6 & 1,19 & 0,95 & 1,50 & 3,64 \\
\hline Odontadenia spoliata Malme & 7 & 1,39 & 0,59 & 1,50 & 3,49 \\
\hline Pouteria gardneri (Mart. \& Miq.) Baehni & 6 & 1,19 & 0,54 & 1,50 & 3,24 \\
\hline Xylopia emarginata Mart. & 6 & 1,19 & 0,37 & 1,20 & 2,77 \\
\hline Inga heterophylla Willd. & 3 & 0,60 & 1,52 & 0,60 & 2,72 \\
\hline Siparuna guianensis Aubl. & 5 & 0,99 & 0,17 & 1,50 & 2,67 \\
\hline Bauhinia outimouta Aubl. & 4 & 0,80 & 0,62 & 1,20 & 2,62 \\
\hline Salacia elliptica (Mart. ex Schult.) G. Don & 5 & 0,99 & 0,35 & 1,20 & 2,55 \\
\hline Outras 43 espécies & 81 & 16,15 & 13,55 & 21,09 & 50,60 \\
\hline Total & 503 & 100,00 & 100,00 & 100,00 & 300,00 \\
\hline
\end{tabular}

Revista Árvore, Viçosa-MG, v.35, n.3, Edição Especial, p.725-735, 2011 
que registraram aumento na biomassa em diversas florestas tropicais no último século e relacionaram isso com o incremento nos níveis de $\mathrm{CO}_{2}$ na atmosfera terrestre. Estudos de longo prazo na mata estudada são essenciais para avaliar se esse padrão se mantém.

As espécies mais importantes que não mudaram de posição hierárquica ou alteraram apenas uma posição em 2006 foram Hymenaea courbaril, Diospyros guianensis, Calophyllum brasiliense e Protium heptaphyllum e as espécies que mudaram duas ou três posições hierárquicas entre os dois períodos estudados, Apuleia leiocarpa, Mabea pohliana e Licania blackii. Merece destaque a posição ocupada por Astrocaryum vulgare, que foi a $5^{\text {a }}$ espécie de maior VI em 1999 e a $1^{\text {a }}$ em 2006. Tetragastris altissima, que passou da $3^{\text {a }}$ para a $9^{a}$ posição, e Physocalymma scaberrimum, que em 1999 ocupava a $8^{a}$ posição e, em 2006, não figurou entre as 10 mais importantes. Considerando que as espécies de maior importância são também as mais abundantes na comunidade, elas apresentariam maior recrutamento, pois seriam mais eficientes para explorar os recursos disponíveis, mantendo assim sua posição hierárquica (FELFILI, 1994; 1995; PINTO; HAY, 2005).

Oenocarpus distichus, espécieexigente deluz(MIGUEL; MARIMON, 2008), que no inventário de 1999 ocupava a $11^{\mathrm{a}}$ posição em VI (28 indivíduos ha-1 e 0,56 $\mathrm{m}^{2} \mathrm{ha}^{-1}$ ) (MARIMON et al., 2002), em 2006 passou a ocupar a sétima posição (32 ind. ha ${ }^{-1} \mathrm{e} 0,66 \mathrm{~m}^{2} \mathrm{ha}^{-1}$ ), possivelmente influenciada por distúrbios que ocorreram na área em 2001 (fogo) e que promoveram a abertura de clareiras que podem ter beneficiado o crescimento e estabelecimento dessa espécie. Tetragastris altissima, por ser tolerante à sombra (MIGUEL; MARIMON, 2008), pode ter sofrido efeito contrário com a abertura da área (clareiras) e maior incidência de luz nas parcelas, visto que em 2006 sofreu redução no número de indivíduos.

Os distúrbios ocasionados pelo fogo, que atingiu a mata em 2001, podem ter causado mudanças na estrutura da vegetação, favorecendo o desenvolvimento de espécies exigentes de luz capazes de suportar maior luminosidade (MIGUEL; MARIMON, 2008). De acordo com Ribeiro e Schiavini (1998) e Felfili et al. (2001ab), queimadas de baixa intensidade costumam causar pouco impacto nas bordas das Matas de Galeria e podem até acentuar sua heterogeneidade, gerando mosaicos de vegetação em diferentes estágios sucessionais, o que permite a coexistência de muitas espécies arbóreas.
Entretanto, a intensidade do fogo pode variar, e em períodos de secas prolongadas os incêndios podem causar danos maiores e se propagar no interior, tal como observado em alguns pontos da mata estudada.

Entre as espécies de maior VI em 2006 e que apresentaram as maiores mudanças hierárquicas em relação a 1999, Astrocaryum vulgare, geralmente está relacionada à perturbação humana (MARIMON et al., 2002), perenifólia, heliófita e seletiva xerófila, que costuma ser comum em áreas degradadas (LORENZI et al., 1996). Ocorre em agrupamentos mais ou menos homogêneos - tanto em formações primárias quanto secundárias -, regenera-se em grande intensidade após as derrubadas e produz anualmente grande quantidade de sementes (LORENZI, 2002). O registro dessa espécie como a de maior importância no levantamento de 2006 confirma os efeitos negativos que podem ter sido causados pela queimada em 2001 nessa porção de mata.

Considerando-se as 77 espécies amostradas no alto em 2006, 14 mantiveram as mesmas posições hierárquicas de VI, 10 mudaram apenas uma posição, 20 mudaram duas ou três posições e 33 mudaram cinco ou mais posições hierárquicas entre os dois períodos estudados (1999 e 2006). Algumas espécies apresentaram mudanças superiores a 10 posições hierárquicas (Tachigali vulgaris, Bauhinia outimouta, Hirtella glandulosa e Ilex affinis), reforçando o caráter dinâmico de algumas populações.

Para Calophyllum brasiliense ( $2^{\mathrm{a}}$ para $3^{\mathrm{a}}$ posição) ocorreu, no entanto, pequena mudança hierárquica entre os inventários, e essa espécie apresenta capacidade de germinação mesmo após vários meses de submersão de suas sementes (MARQUES; JOLY, 2000) e ciclo constante na produção de frutos (SCHIAVINI et al., 2001). Na mata estudada, os indivíduos de C. brasiliense costumam estar localizados na margem do córrego, em parcelas com solo mais úmido (MARIMON et al., 2003), provavelmente tendo sido menos afetados pela queimada de 2001.

Em 2006, os indivíduos mortos em pé representaram $5,4 \%$ da densidade total e 4,7\% da área basal. No inventário de 1999, os mortos representaram 4,8\% e 4,1\%, respectivamente (MARIMON et al., 2002), confirmando que houve aumento dos indivíduos mortos entre os dois períodos, provavelmente causado pela queimada de 2001. 


\subsection{Porção do meio}

A densidade absoluta na porção do meio, em 2006, foi de 864 ind. ha ${ }^{-1}$ e a área basal, de $22,12 \mathrm{~m}^{2} \mathrm{ha}^{-1}$. As 10 espécies de maior valor de importância (VI) representaram 39\% do VI total, 36\% do número de indivíduos e 49\% da área basal total (Tabela 2). Aspidosperma subincanum apresentou a maior densidade e Hymenaea courbaril, a maior dominância (Tabela 2).
Comparando com o inventário de 1999, em que a densidade absoluta foi de 938 ind. ha-1 e a área basal de 21,64 m² ha-1 (MARIMON et al., 2002), em 2006 foram registrados redução na densidade e aumento na área basal, caracterizando uma situação de autodesbaste, como observado por Werneck et al. (2000). As espécies mais importantes que não mudaram de posição hierárquica ou alteraram apenas uma posição em 2006 foram Tetragastris altissima, Vitex polygama, Pouteria gardneri, Apuleia leiocarpa, P. torta, Ephedranthus parviflorus,

Tabela 2 - Parâmetros fitossociológicos das espécies principais amostradas na porção do meio na Mata de Galeria do córrego Bacaba, Nova Xavantina, MT. Sendo: N = número de indivíduos, DR = Densidade relativa (\%), DoR = Dominância relativa (\%), FR = Frequência relativa (\%) e VI = Valor de importância

Table 2 - Phytosociological parameters for principal species sampled in the middle portion of the Bacaba gallery forest, Nova Xavantina-MT. $N=$ number of individuals, $D R=$ relative density $(\%), D o R=$ relative dominance $(\%), F R$ $=$ relative frequency $(\%)$ and $V I=$ importance value

\begin{tabular}{|c|c|c|c|c|c|}
\hline Espécies & $\mathrm{N}$ & DR & DoR & FR & VI \\
\hline Aspidosperma subincanum Mart. & 27 & 6,65 & 3,33 & 4,66 & 14,64 \\
\hline Tetragastris altissima (Aubl.) Swart. & 21 & 5,17 & 4,35 & 4,66 & 14,18 \\
\hline Hymenaea courbaril L. & 8 & 1,97 & 9,72 & 1,86 & 13,56 \\
\hline Apuleia leiocarpa (Vog.) Macbr. & 10 & 2,46 & 7,85 & 3,11 & 13,42 \\
\hline Pouteria torta (Mart.) Radlk. & 6 & 1,48 & 9,58 & 1,86 & 12,92 \\
\hline Ephedranthus parviflorus S. Moore & 22 & 5,42 & 1,86 & 4,04 & 11,31 \\
\hline Vitex polygama Cham. & 4 & 0,99 & 8,04 & 1,24 & 10,27 \\
\hline Protium heptaphyllum (Aubl.)Marchand & 20 & 4,93 & 1,51 & 3,73 & 10,17 \\
\hline Luehea candicans Mart. & 15 & 3,69 & 1,00 & 3,42 & 8,11 \\
\hline Pouteria gardneri (Mart. \& Miq.) Baehni & 13 & 3,2 & 2,09 & 2,80 & 8,09 \\
\hline Tachigali vulgaris L.G. Silva \& H.C. Lima & 9 & 2,22 & 2,54 & 2,17 & 6,93 \\
\hline Platypodium elegans Vogel. & 10 & 2,46 & 1,19 & 2,48 & 6,14 \\
\hline Bauhinia outimouta Aubl. & 10 & 2,46 & 0,83 & 2,48 & 5,78 \\
\hline Protium spruceanum (Benth.) Engl. & 7 & 1,72 & 2,46 & 1,55 & 5,74 \\
\hline Mabea pohliana (Benth.) Müll. Arg. & 10 & 2,46 & 0,76 & 2,48 & 5,70 \\
\hline Unonopsis lindmanii R.E. Fr. & 11 & 2,71 & 1,08 & 1,86 & 5,65 \\
\hline Anadenanthera colubrina (Vell.) Brenan & 6 & 1,48 & 2,30 & 1,86 & 5,64 \\
\hline Calophyllum brasiliense Cambess & 2 & 0,49 & 4,36 & 0,62 & 5,47 \\
\hline Copaifera langsdorffii Desf. & 2 & 0,49 & 4,35 & 0,62 & 5,46 \\
\hline Coussarea platyphylla Müll. Arg. & 11 & 2,71 & 0,87 & 1,86 & 5,44 \\
\hline Alibertia elliptica (Cham.) K. Schum. & 9 & 2,22 & 0,67 & 2,48 & 5,37 \\
\hline Astronium fraxinifolium Schott. & 7 & 1,72 & 1,34 & 2,17 & 5,23 \\
\hline Tabebuia impetiginosa (Mart. ex.DC.) Standl. & 3 & 0,74 & 3,56 & 0,96 & 5,23 \\
\hline Cuspidaria sp. & 8 & 1,97 & 0,63 & 2,17 & 4,78 \\
\hline Sterculia striata A. St.-Hil \& Naudin & 3 & 0,74 & 2,96 & 0,93 & 4,63 \\
\hline Licania blackii Prance & 6 & 1,48 & 1,54 & 1,55 & 4,57 \\
\hline Inga thibaudiana DC. & 6 & 1,48 & 1,83 & 1,24 & 4,55 \\
\hline Physocalymma scaberrimum Pohl. & 6 & 1,48 & 1,02 & 1,86 & 4,36 \\
\hline Aiouea saligna Meisn. & 7 & 1,72 & 0,44 & 1,86 & 4,03 \\
\hline Bauhinia longifolia D.Dietr. & 6 & 1,48 & 0,56 & 1,86 & 3,90 \\
\hline Combretum vernicosum Rusby & 6 & 1,48 & 0,56 & 1,86 & 3,90 \\
\hline Xylopia aromatica (Lam.) Mart. & 6 & 1,48 & 0,48 & 1,86 & 3,82 \\
\hline Oenocarpus distichus Mart. & 5 & 1,23 & 1,31 & 1,24 & 3,78 \\
\hline Pseudolmedia laevigata Trécul & 6 & 1,48 & 0,52 & 1,24 & 3,24 \\
\hline Outras 54 espécies & 98 & 24,14 & 12,51 & 27,36 & 63,99 \\
\hline Total & 406 & 100,00 & 100,00 & 100,00 & 300,00 \\
\hline
\end{tabular}

Revista Árvore, Viçosa-MG, v.35, n.3, Edição Especial, p.725-735, 2011 
Luehea candicans e Protium heptaphyllum. Hymenaea courbaril passou da $1^{\mathrm{a}}$ para a $3^{\mathrm{a}}$ posição em 2006 e Aspidosperma subincanum, da $6^{\mathrm{a}}$ para a $1^{\mathrm{a}}$.

Considerando-se as 88 espécies amostradas no meio em 2006, sete mantiveram as mesmas posições hierárquicas de VI, 10 mudaram apenas uma posição, nove mudaram duas ou três posições e 62 mudaram cinco ou mais posições hierárquicas entre os dois períodos estudados (1999 e 2006). Tal como observado na porção do alto, esta também apresentou espécies com mudanças hierárquicas marcantes. Cecropia pachystachya passou da 20a posição em 1999 para a $49^{\mathrm{a}}$ em 2006, e Bauhinia outimouta passou da $45^{\mathrm{a}}$ para a $10^{\text {a }}$, respectivamente. C. pachystachya é espécie pioneira, típica de áreas abertas, prefere matas secundárias, mas também pode ser encontrada em capoeiras novas situadas em vertentes ou cursos d’água e em terrenos com lençol freático superficial (OLIVEIRAFILHO; RATTER, 1995; LORENZI, 2002). A redução no número de indivíduos dessa espécie entre os dois inventários sugere que esteja ocorrendo o fechamento da vegetação nessa porção de mata (GUARINO; WALTER, 2005).

Sugere-se ainda que Aspidosperma subincanum, que passou da $6^{\mathrm{a}}$ posição de VI em 1999 para a $1^{\mathrm{a}}$ em 2006, pode estar refletindo uma condição de proteção, tendo sido beneficiada pela implantação do Parque Municipal do Bacaba (Lei Municipal nº 652, de 27/12/ 1995). Nas demais porções de mata (alto e baixo), $A$. subincanum também passou a ocupar posição de importância maior em 2006. Antes da criação dessa unidade de conservação, essa espécie era cortada para a confecção de cabos de ferramentas, porém atualmente não se encontra mais sob pressão de corte.

Entre as espécies mais importantes na porção do meio, também se destaca Hymenaea courbaril, que desceu da $1^{\mathrm{a}}$ para a $3^{\mathrm{a}}$ posição em 2006 , em função da morte de dois indivíduos de grande porte. Não é possível afirmar com certeza que a morte tenha sido causada pela queimada em 2001. Entretanto, essa espécie, diferente do que é observado na congenérica típica de cerrado sentido restrito (Hymenaea stigonocarpa) (SILVA-JÚNIOR, 2005), não apresenta ritidoma espesso que pode proteger o tronco do fogo. Nesse caso, supõe-se que a queimada que atingiu a mata em 2001 pode ter contribuído para a morte dos referidos indivíduos.
Em 2006, os indivíduos mortos em pé registrados na porção do meio representaram 19,3\% da densidade total e 1,9\% da área basal. No inventário realizado em 1999 (MARIMON et al., 2002), os mortos corresponderam a apenas 2,4\% da densidade e 2,8\% da área basal total, registrando-se aumento no número e redução na área basal de indivíduos mortos em 2006. Da mesma forma como descrito para a porção do alto, sugere-se que os impactos causados pelo fogo que atingiu a mata em 2001 sejam responsáveis pelo aumento da mortalidade de indivíduos jovens, visto que em 1999 a maior área basal e a menor densidade registradas com plantas mortas poderiam estar relacionadas com árvores adultas e velhas.

\subsection{Porção do baixo}

A densidade absoluta na porção do baixo, em 2006, foi de 1.079 ind. ha-1 ${ }^{-1}$ com uma área basal de $25,50 \mathrm{~m}^{2} \mathrm{ha}^{-1}$. As 10 espécies mais importantes representaram $62 \%$ do VI total, $61,5 \%$ do número de indivíduos e 73,6\% da área basal total (Tabela 3). A espécie de maior VI, Mauritia flexuosa, apresentou dominância cerca de sete vezes superior à segunda espécie com maior VI (Astrocaryum vulgare), que por sua vez teve a maior densidade e frequência (Tabela 3).

Em comparação com o inventário de 1999, quando a densidade absoluta foi de 1.257 ind. ha $^{-1}$ e a área basal de 22,63 m² ha-1 (MARIMON et al., 2002), em 2006 foram registrados redução na densidade e aumento na área basal, em um padrão similar ao registrado na porção do meio. Mauritia flexuosa foi a única espécie entre as mais importantes que não mudou a posição hierárquica, sendo Astrocaryum vulgare e Mabea pohliana as que alteraram apenas uma posição em 2006. As mudanças mais expressivas foram registradas em Cecropia pachystachya ( $2^{\mathrm{a}}$ posição em 1999 para a $11^{\mathrm{a}}$ em 2006), Himatanthus bracteatus $\left(10^{\mathrm{a}}\right.$ para $\left.5^{\mathrm{a}}\right)$, Ormosia excelsa $\left(15^{\mathrm{a}}\right.$ para $\left.10^{\mathrm{a}}\right)$, Virola urbaniana $\left(7^{\mathrm{a}}\right.$ para $3^{\mathrm{a}}$ ) e Aspidosperma subincanum (13 ${ }^{\mathrm{a}}$ para $\left.9^{\mathrm{a}}\right)$. H. bracteatus, V. urbaniana e Physocalymma scaberrimum são exemplos de espécies exigentes de luz (MIGUEL; MARIMON, 2008), que, provavelmente, foram beneficiadas com aumento no crescimento (o número de indivíduos sofreu pouca alteração), em razão da maior entrada de luz na mata, resultante da queimada que ocorreu em 2001. No entanto, C. pachystachya perdeu posições provavelmente por ser espécie pioneira (OLIVEIRA-FILHO; RATTER, 1995; LORENZI, 2002; 
GUARINO; WALTER, 2005) e estar refletindo atualmente uma condição de recuperação pós-distúrbio. Hallé et al. (1978) observaram que, quando isso ocorre, a comunidade (ou população) estaria na fase de “construção” do ciclo silvigenético.

Essa porção de mata, apesar de ser a única onde a espécie de maior VI em 1999 também se manteve na primeira posição em 2006, apresentou grandes mudanças nas posições hierárquicas das demais espécies, com algumas desaparecendo da mata, algumas novas sendo registradas (MIGUEL; MARIMON, 2008) e outras alterando até 35 posições (ex.: Mauritiella armata) em relação ao levantamento de 1999.

Considerando-se as 71 espécies amostradas no baixo em 2006, apenas uma (Mauritia flexuosa) manteve a mesma posição hierárquica de VI, duas mudaram apenas uma posição, 16 mudaram duas ou três posições hierárquicas e 52 mudaram cinco ou mais posições entre

Tabela 3 - Parâmetros fitossociológicos das espécies principais amostradas na porção do baixo na Mata de Galeria do córrego Bacaba, Nova Xavantina, MT. Sendo: N = número de indivíduos, DR = Densidade relativa (\%), DoR = Dominância relativa (\%), FR = Frequência relativa (\%) e VI = Valor de importância

Table 3 - Phytosociological parameters for principal species sampled in the lower portion of the Bacaba gallery forest, Nova Xavantina-MT. $N=$ number of individuals, $D R=$ relative density $(\%), D o R=$ relative dominance $(\%), F R$ = relative frequency $(\%)$ and $\mathrm{VI}=$ importance value

\begin{tabular}{|c|c|c|c|c|c|}
\hline Espécies & $\mathrm{N}$ & DR & DoR & FR & VI \\
\hline Mauritia flexuosa L.f. & 46 & 9,07 & 41,74 & 6,94 & 57,75 \\
\hline Astrocaryum vulgare Mart. & 69 & 13,61 & 6,32 & 7,26 & 27,19 \\
\hline Virola urbaniana Warb. & 40 & 7,89 & 3,00 & 4,73 & 15,62 \\
\hline Physocalymma scaberrimum Pohl. & 28 & 5,52 & 3,78 & 6,31 & 15,62 \\
\hline Himatanthus bracteatus (A.DC.) Woodson & 29 & 5,72 & 3,27 & 5,36 & 14,36 \\
\hline Tapirira guianensis Aubl. & 17 & 3,35 & 5,38 & 4,42 & 13,15 \\
\hline Mabea pohliana (Benth.) Müll. Arg. & 26 & 5,13 & 1,74 & 5,36 & 12,23 \\
\hline Xylopia aromatica (Lam.) Mart. & 23 & 4,54 & 2,92 & 4,42 & 11,87 \\
\hline Aspidosperma subincanum Mart. & 19 & 3,75 & 2,48 & 3,15 & 9,38 \\
\hline Ormosia excelsa Benth. & 15 & 2,96 & 2,98 & 2,84 & 8,78 \\
\hline Cecropia pachystachya Trécul & 17 & 3,35 & 1,80 & 2,84 & 8,00 \\
\hline Cordia sellowiana Cham. & 11 & 2,17 & 2,91 & 2,84 & 7,92 \\
\hline Tetragastris altissima (Aubl.) Swart. & 10 & 1,97 & 1,60 & 2,21 & 5,78 \\
\hline Vitex polygama Cham. & 7 & 1,38 & 1,38 & 1,58 & 4,34 \\
\hline Coussarea platyphylla Müll. Arg. & 7 & 1,38 & 1,31 & 1,58 & 4,27 \\
\hline Schefflera morototoni (Aubl.) Mag., Steyerm. \& Frodin & 6 & 1,18 & 1,74 & 1,26 & 4,19 \\
\hline Myrcia sellowiana O. Berg. & 8 & 1,58 & 0,60 & 1,58 & 3,76 \\
\hline Bauhinia longifolia D.Dietr. & 7 & 1,38 & 0,48 & 1,89 & 3,76 \\
\hline Inga thibaudiana DC. & 5 & 0,99 & 1,13 & 1,58 & 3,70 \\
\hline Casearia sylvestris Sw. & 10 & 1,97 & 0,41 & 1,26 & 3,64 \\
\hline Protium heptaphyllum (Aubl.)Marchand & 8 & 1,58 & 0,34 & 1,58 & 3,49 \\
\hline Curatella americana L. & 5 & 0,99 & 1,03 & 1,26 & 3,28 \\
\hline Tachigali vulgaris L.G. Silva \& H.C. Lima & 2 & 0,39 & 2,12 & 0,63 & 3,14 \\
\hline Luehea candicans Mart. & 6 & 1,18 & 0,54 & 1,26 & 2,98 \\
\hline Cariniana rubra Gardner ex Miers & 4 & 0,79 & 0,34 & 1,26 & 2,39 \\
\hline Trema micrantha (L.) Blume & 4 & 0,79 & 0,25 & 1,26 & 2,30 \\
\hline Sterculia speciosa K. Schum. & 2 & 0,39 & 1,21 & 0,63 & 2,23 \\
\hline Apeiba tibourbou Aubl. & 2 & 0,39 & 0,86 & 0,63 & 1,89 \\
\hline Siparuna guianensis Aubl. & 3 & 0,59 & 0,32 & 0,95 & 1,86 \\
\hline Bauhinia outimouta Aubl. & 3 & 0,59 & 0,31 & 0,95 & 1,85 \\
\hline Licania gardneri (Hook.f.) Fritsch & 3 & 0,59 & 0,53 & 0,63 & 1,75 \\
\hline Hirtella glandulosa Spreng. & 3 & 0,59 & 0,16 & 0,95 & 1,70 \\
\hline Apuleia leiocarpa (Vog.) Macbr. & 3 & 0,59 & 0,13 & 0,95 & 1,67 \\
\hline Qualea multiflora Mart. & 3 & 0,59 & 0,10 & 0,95 & 1,64 \\
\hline Outras 37 espécies & 56 & 11,07 & 4,79 & 16,70 & 32,52 \\
\hline Total & 507 & 100,00 & 100,00 & 100,00 & 300,00 \\
\hline
\end{tabular}

Revista Árvore, Viçosa-MG, v.35, n.3, Edição Especial, p.725-735, 2011 
os dois períodos estudados. Mauritia flexuosa é comumente encontrada em áreas brejosas ou permanentemente inundadas do Brasil central (OLIVEIRAFILHO; RATTER, 1995) e ocorre em agrupamentos quase homogêneos (buritizais) (LORENZI, 2002). Astrocaryum vulgare, ao contrário do que foi registrado na porção do alto, esteve entre as espécies com pequenas alterações hierárquicas nessa porção. Tapirira guianensis também apresentou pouca mudança hierárquica, confirmando o que já foi observado por Oliveira-Filho e Ratter (1995), que a consideram uma espécie cosmopolita com alta plasticidade em termos ambientais.

Convém salientar que, na porção do baixo, a expressiva mudança de posições hierárquicas registrada na maioria das espécies, em comparação com as porções do alto e do meio, também pode estar sendo ocasionada por distúrbios ligados às inundações e ao afloramento do lençol freático no período chuvoso (MARIMON et al., 2003). Rodrigues (2000) apresentou a elevação do curso d’água e, ou, do lençol freático como um processo de perturbação natural nas formações ribeirinhas, tornando mais complexa a dinâmica sucessional dessas áreas, pois esses fatores podem causar alterações decorrentes da deposição de sedimentos, soterramento ou retirada da serapilheira e do banco de sementes. Esse autor observou ainda que as espécies apresentam performance diferencial ao encharcamento sazonal, tal como observado em Mauritia flexuosa, espécie de maior importância nessa porção e típica de áreas alagadas.

Os indivíduos mortos em pé, em 2006, representaram na porção do baixo $4 \%$ da densidade e 2,6\% da área basal total. No inventário de 1999 , os mortos corresponderam a 6,9\% da densidade e 3,5\% da área basal total (MARIMON et al., 2002). A redução na densidade e área basal dos mortos em 2006 pode sugerir que essa porção foi menos afetada pela queimada que ocorreu em 2001 e se encontra atualmente em estágio de recuperação pós-distúrbio, tal como discutido anteriormente.

\section{CONCLUSÃO}

As três porções estudadas na Mata de Galeria do córrego Bacaba apresentaram mudanças na estrutura da vegetação lenhosa no período analisado (1999 e 2006). Em um intervalo de sete anos, observou-se que a ordem das espécies sofreu alterações hierárquicas em maior ou menor intensidade. Esse aspecto reforça que essa mata é dinâmica, sendo resiliente em algumas porções e em relação a algumas populações e resistente em outras. As espécies de maior VI registradas na mata estudada também são registradas como importantes em outros estudos realizados em florestas ribeirinhas.

Entre as 10 espécies de maior VI neste estudo, nenhuma foi comum às três porções da Mata de Galeria do córrego Bacaba. As características ambientais heterogêneas das porções de mata estudadas, apesar de muito próximas geograficamente (cerca de 300 m), por certo determinaram as características estruturais distintas da vegetação.

Baseando na composição florística e nas características estruturais de cada porção da Mata de Galeria do córrego Bacaba, sugere-se que essas porções tenham sido afetadas de forma diferenciada pela queimada que atingiu a área em 2001. A porção do alto, por se encontrar em terreno com maior declive e solo de menor umidade, pode ter sido a mais afetada pelo fogo, visto que uma espécie típica de ambientes antropizados (Astrocaryum vulgare) passou a ocupar a primeira posição de importância na comunidade, em comparação com o levantamento realizado antes da passagem do fogo (1999). No entanto, o baixo, apesar de ter sofrido grandes mudanças estruturais nas populações, provavelmente por apresentar condições de maior umidade no solo, tenha conseguido recuperar a estrutura da vegetação mais rapidamente após a passagem do fogo, visto que a posição hierárquica de algumas espécies pioneiras declinou no período estudado, indicando que a vegetação se encontrava em fase de fechamento pós-distúrbio, aumentando o sombreamento das espécies no subbosque.

\section{AGRADECIMENTOS}

À CAPES, pela bolsa concedida à primeira autora; e à FAPEMAT (Projeto: Tecnologia de bases ecológicas para a recomposição, uso sustentável de florestas de galeria e proteção de recursos hídricos, Proc. № 0738/ 2006), pelo auxílio financeiro.

\section{REFERÊNCIAS}

BAKER, T. R. et al. Increasing biomass in Amazonian forest plots. Philosophical Transactions of the Royal Society B, v.359, p.353-365, 2004. 
BALCH, J. K. et al. Negative fire feedback in a transitional forestvof southeastern Amazonia. Global Change Biology, v.14, p.2276-2287, 2008.

BATTILANI, J. L.; SCREMIN-DIAS, E.; SOUZA, A. L. T. Fitossociologia de um trecho da mata ciliar do rio da Prata, Jardim, MS, Brasil. Acta Botanica Brasilica, v.19, n.3, p.597-608, 2005.

FELFILI, J. M. Floristic composition and phytosociology of the gallery forest alongside the Gama stream in Brasília, DF, Brasil. Revista Brasileira de Botânica, v.17, n.1, p.1-11, 1994.

FELFILI, J. M. Diversity, structure and dynamics of a gallery forest in central Brazil. Vegetatio, v.117, n.1, p.1-15, 1995.

FELFILI, J. M. et al. Flora fanerogâmica das Matas de Galeria e Ciliares do Brasil Central. In: RIBEIRO, J. F.; FONSECA, C. E. L.; SOUSASILVA, J. C. (Eds.). Cerrado: caracterização e recuperação de Matas de Galeria. Planaltina: Embrapa Cerrados, 2001a. p.195-263.

FELFILI, J. M. et al. Desenvolvimento inicial de espécies de mata de galeria. In: RIBEIRO, J. F.; FONSECA, C. E. L.; SOUSA-SILVA, J. C. (Eds.). Cerrado: caracterização e recuperação de Matas de Galeria. Planaltina: Embrapa Cerrados, 2001b. p.779-811.

GUARINO, E. S. G.; WALTER, B. M. Fitossociologia de dois trechos inundáveis no Distrito Federal, Brasil. Acta Botanica Brasilica, v.19, n.3, p.431-442, 2005.

HALLÉ, F.; OLDEMAN, R. A. A.; TOMLINSON, P. B. Tropical trees and forests. Berlin: Springer-Verlag, 1978. 483p.

LORENZI, H. Árvores brasileiras: manual de identificação e cultivo de plantas arbóreas nativas do Brasil. Nova Odessa: Plantarum, 2002. v.1.53p.

LOREnZI, H. et al. Palmeiras no Brasil. Nova Odessa: Plantarum, 1996. 303p.

MARIMON, B. S. et al. Distribuição de circunferências e alturas em três porções da mata de galeria do Córrego Bacaba, Nova Xavantina-MT. Revista Árvore, v.25, n.3, p.335-343, 2001.
MARIMON, B. S.; FELFILI. J. M.; LIMA, E. S. Floristic and phytosociology of the gallery forest of the Bacaba stream, Nova Xavantina, Mato Grosso, Brasil. Edinburgh Journal of Botany, v.59, n.2, p.303-318, 2002.

MARIMON, B. S. et al. Padrões de distribuição de espécies na Mata de Galeria do Córrego Bacaba, Nova Xavantina, Mato Grosso, em relação a fatores ambientais. Boletim do Herbário Ezechias Paulo Heringer, v.12, n.1, p.1-10, 2003.

MARIMON, B. S. et al. Observations on the vegetation of northeastern Mato Grosso, Brazil. IV. an analysis of the cerrado-amazonian forest ecotone. Edinburgh Journal of Botany, v.63, p.323-341, 2006.

MARIMON, B. S. et al. Environmental determinants for natural regeneration of gallery forest at the Cerrado/Amazonia boundaries in Brazil. Acta Amazonica, v.40, n.1, p.107-118, 2010.

MARQUES, M. C. M.; JOLY, C. A. Estrutura e dinâmica de uma população de Calophyllum brasiliense Camb. Em floresta higrófila do sudeste do Brasil. Revista Brasileira de Botânica, v.23, n.1, p.107-112, 2000.

MELO, A. C. G.; MIRANDA, D. L. C.; DURIGAN, G. Cobertura de copas como indicador de desenvolvimento estrutural de reflorestamentos de restauração de matas ciliares no Médio Vale do Paranapanema, SP, Brasil. Revista Árvore, v.31, n.3, p.321-328, 2007.

MIGUEL, A.; MARIMON, B. S. Mudanças na composição florística e na biodiversidade de espécies em três áreas da mata de galeria do córrego Bacaba (Nova Xavantina, MT). In: SANTOS, J. E.; GALBIATI, C. (Orgs.). Gestão e educação ambiental; água, biodiversidade e cultura. São Carlos: Rima, 2008. v.1. (no prelo).

MOBOT. Missouri Botanical Garden's (VAST-Vascular Tropicos). Acesso em 10/ 07/2007. http://mobot.mobot.org/W3T/Search/ vast.html.

MÜlLER-DOMBOIS, D.; ELLEMBERG, H. Aims and methods of vegetation ecology. New York: John Wiley, 1974. 
NEPSTAD, D. et al. Frontier Governance in Amazonia. Science, v.295, p.629-630, 2002.

NEPSTAD, D. et al. Amazon drought and its implications for forest flammability and tree growth: a basin-wide analysis. Global Change Biology, v.10, p.704-717, 2004.

OLIVEIRA-FILHO, A. T. Composição florística e estrutura comunitária da Floresta de Galeria do córrego da Paciência, Cuiabá, (MT). Acta

Botanica Brasilica, v.3, n.1, p.91-112, 1989.

OLIVEIRA, E. C. L.; FELFILI, J. M. Estrutura e dinâmica da regeneração natural de uma mata de galeria no Distrito Federal, Brasil. Acta

Botanica Brasilica, v.19, n.4, p.801-811, 2005.

OLIVEIRA-FILHO, A. T.; RATTER, J. A. A study of the origin of central Brazilian forests by the analysis of plant species distribution patterns. Edinburgh Journal of Botany, v.52, n.2, p.141-194, 1995.

PHILLIPS, O. L.; GENTRY, A. H. Increasing turnover through time in tropical forests. Science, v.263, p.954-958, 1994.

PINTO, J. R. R. Dinâmica da comunidade arbórea-arbustiva em uma floresta de vale no Parque Nacional da Chapada dos Guimarães, Mato Grosso. 2002. 105p Tese (Doutorado em Ecologia) - Universidade de Brasília, Brasília, 2002.

PINTO, J. R. R.; OLIVEIRA-FILHO, A. T. Perfil florístico da comunidade arbórea de uma floresta de vale no Parque Nacional da Chapada dos Guimarães, Mato Grosso, Brasil. Revista Brasileira de Botânica, v.22, n.1, p.53-67, 1999.

PINTO, J. R. R.; HAY, J. D. V. Mudanças florísticas e estruturais na comunidade arbórea de uma floresta de vale no Parque Nacional da Chapada dos Guimarães, Mato Grosso, Brasil. Revista Brasileira de Botânica, v.28, n.3, p.523-539, 2005.
RODRIGUES, R. R. Florestas Ciliares: uma discussão nomenclatural das formações ciliares. In: RODRIGUES, R. R.; LEITÃO FILHO, H. F., (Eds.). Matas Ciliares: conservação e recuperação. São Paulo: Universidade de São Paulo/Fapesp, 2000. p.91-107.

RIBEIRO, J. F.; SCHIAVINI, I. Recuperação de matas de galeria: integração entre a oferta ambiental e a biologia das espécies. In: RIBEIRO, J. F. (Ed.). Cerrado: matas de galeria.

Planaltina: Embrapa-CPAC, 1998. p.137-153.

SCHIAVINI, I.; RESENDE, J. C. F.; AQUINO, F. G. Dinâmica de populações de espécies arbóreas em Mata de Galeria e Mata Mesófila na margem do Ribeirão Panga, MG. In: RIBEIRO, J. F.;

FONSECA, C. E. L.; SOUSA-SILVA, J. C. (Eds.). Cerrado: caracterização e recuperação de Matas de Galeria. Planaltina: Embrapa-Cerrado, 2001. p.267-299.

SHEPHERD, G. J. FITOPAC 1 - Manual do Usuário. Campinas: UNICAMP, 1994. 88p.

SILVA-JÚNIOR, M. C. 100 árvores do cerrado. Brasília: Rede de Sementes do Cerrado, 2005. 278p.

SILVA-JÚNIOR, M. C. et al. Análise da flora de Matas de Galeria no Distrito Federal: 21 levantamentos. In: RIBEIRO, J. F.; FONSECA, C. E. L.; SOUSA-SILVA, J. C. (Eds.). Cerrado: caracterização e recuperação de Matas de Galeria. Planaltina: Embrapa-Cerrado, 2001. p.143-191.

van den BERG, E. V. D.; OLIVEIRA-FILHO, A. T. Composição fitossociológica de uma floresta ripária em Itutinga, MG, e comparação com outras áreas. Revista Brasileira de Botânica, v.23, n.3, p.231-253, 2000.

WERNECK, M. S.; FRANCESCHINELLI, E. V.; TAMEIRÃO-NETO, E. Mudanças na florística e estrutura de uma floresta decídua durante um período de quatro anos (1994-1998), na região do Triângulo Mineiro, MG. Revista Brasileira de Botânica, v.23, n.4, p.401-413, 2000. 
